\title{
Editorial
}

\section{Boundary Value Problems on Time Scales}

\author{
Alberto Cabada and Victoria Otero-Espinar \\ Departamento de Análise Matemática, Facultade de Matemáticas, Universidade de Santiago de Compostela, \\ 15782 Santiago de Compostela, Galicia, Spain
}

Correspondence should be addressed to Alberto Cabada, alberto.cabada@usc.es

Received 3 November 2009; Accepted 3 November 2009

Copyright (C 2009 A. Cabada and V. Otero-Espinar. This is an open access article distributed under the Creative Commons Attribution License, which permits unrestricted use, distribution, and reproduction in any medium, provided the original work is properly cited.

This volume includes nineteen papers on the relatively recent topic of the study of dynamic equations on a time scale. This theory goes back to its founder Stefan Hilger (1988), and is a new area of still fairly theoretical exploration in mathematics. Motivating the subject is the notion that dynamic equations on time scales can build bridges between continuous and discrete mathematics; moreover, often it revels the reasons for the discrepancies between both theories.

This monograph is directed to different kinds of boundary value problems and contains new researches on the existence, uniqueness, and multiplicity of solutions of different types of problems as $m$-point, $p$-laplacian, or higher-order equations together with functional and impulsive equations with singularities.

The arguments used vary from comparison principles, degree theory or variational methods to approximation theory. In all papers, some physical or medical mathematical models are considered.

We would like to express our gratitude to all the participants, who made possible a very stimulating interchange of ideas.

Alberto Cabada and Victoria Otero-Espinar Santiago de Compostela

October 2009 